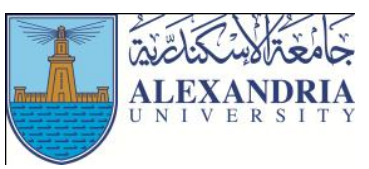

\author{
Journal of Applied Sports Science \\ December 2016, Volume 6, No. 4 \\ www.jass.alexu.edu.eg
}

\title{
A Recreational Games Program for Improving Social Skills for School Bully Victims
}

\author{
Ahmed Mohamed Shawkey Ibrahim ${ }^{1}$ \\ ${ }^{1}$ Lecturer, Department of Administration and Recreation Sports - Faculty of Physical Education - Tanta University
}

\begin{abstract}
The current research aims to improve social skills of school bullying victims and decrease the phenomenon of school bullying victims through a recreational games program. The researcher used the experimental approach (one-group design) with pre- and post-measurements. Participants $(n=28)$ were purposefully chosen. They were all school bullying victims with stable middle class families. The researcher applied the program for (8) continuous weeks and pre-and post-measurements were made using Matson's Evaluation of Social Skills for Youngsters Scale and Bullying Victim Scale by Frienden et al., Arabicized and calibrated for the Egyptian environment. Results indicated that there were statistically significant differences between pre-and pot-measurements of participants on improving social skills of school bullying victims with Improvement percentage $137.43 \%$ and decreasing the school bullying victims' phenomenon with Improvement percentage $71.41 \%$, as the recommended recreational games program had positive effects.
\end{abstract}

Keywords: Recreational Games - Social Skills - School Bullying Victims

\section{Introduction and Research Problem:}

$\mathrm{E}$ veryone has the right to live happily with dignity. Bullying ruins peace and safety of individuals and brings stress, anxiety, depression and fear to them. School bullying is a common behavioral problem in schools. It is one of the most serious problems due to its various aspects as it includes psychological, social and economic effects on both the individual and the society as well.

Bullying varies in degree from aggression. Bullying is on the aggression continuum as it is preceded by riot and followed by violence. The motive behind aggressive behavior is anger. The image of those who are involved in aggression implies that they express anger to others, while in bullying, the bully harasses the victim on purpose. The aggressive student involves in this behavior due to anger situation while the bully does so continuously on purpose to subdue the victim (Hopkins et al 2013).

At school environment, the victim of bullying is often a lonely child who is harassed by a group of two or three with a passive leader. A significant portion of victims (20$40 \%$ ) indicated that they were victims of a single bully (Allen 2010).

Characteristics of bully victims include vulnerability to fall. The victim is easy-to deceive and can't defend himself in addition to other physical and mental characteristics and lack of support. The victim feels weak and isolated and sometimes denies the accident to avoid revenge of the bully (Chin-Tsai Kuo 2013).

Bully victims have low self-esteem, a few number of friends, feeling of failure and anxiety, lack of selfconfidence and weak body. This makes them more vulnerable to attacks. They are unable to form relationships with peers and they tend to be isolated. This makes them feel lonely and neglected in addition to anxiety, fears and insecurity. They fear to go to school and are unable to focus. This causes several physical and mental symptoms (Debra et al 2006).

Bully victims have no friends due to the severe lack of social skills. Bully victims can be categorized into passive victims who surrender to aggression and do not defend themselves with withdrawal tendencies and feelings of fear, suspicion and caution towards peers. The other type is provocative victims who provoke the bully through shape, clothes, movement and behaviors of voyeur, eavesdropping and curiosity. Provocative victims are often neglected by peers and lack social skills. They tend to be alienated from classmates and fail to defend themselves in addition to being lonely (Archer et al 2007). They suffer from low social behavior, social dissatisfaction, loneliness and isolation (Schwartz et al 2002). Their social skills are 
weak (Fox \& Boulton 2005). They find it hard to make new friendships, suffer from various mental health problems and need preventive programs (Alikasifoglu et al 2007). They suffer from various psychological problems including low self-confidence, worthlessness and low selfrespect (Agnes et al 2009).

The researcher thinks that this lack of social skills has negative effects on school bullying victims. Therefore, we need to design sports programs in general and especially sports recreation programs that work on improving social skills for this category of individuals to enable them lead normal life socially and psychologically. This may decrease the school bullying phenomenon.

Sports participation improves the character strength and the ability to self-defense in addition to assertiveness and how to deal with bully students. In addition, it improves social and self-awareness, security and satisfaction and teaches students how to retaliate physical aggression, how to resolve conflicts and how to void bully students. It teaches them how to behave when they become bully victims and how to defend their rights firmly and without fear (Shapiro 2004).

Games improve social awareness, social interaction, selfconfidence, self-satisfaction and making friendships (Pettry 2006). Recreational games and activities protects individuals from boring, anxiety, depression and stress. Individuals express themselves, make friendships, cooperate and interact with others, improve their physical, mental, social and psychological health, achieve happiness, self-satisfaction and content and modify their attitudes towards a shiny happy life (Taha 2006, Tolba 2010). It improves general health as it is a good and successful way to support health, increase activity level and acquire experiences and information (Chih et al 2009, Sylvia et al 2014). It improves quality of life as it increases happiness, comfort, and physical fitness and decreases stress and anxiety in addition to improving selfexpression, formation of new friendships, cooperation, self-satisfaction, self-assertiveness, social acceptance, interaction with others, intellectual development, gaining knowledge and experiences, problem solving, achievement, quality of life and mental, physical, social and psychological health (Kraus 2015).

Social skills are the backbone of successful character. It helps individuals in everyday interaction like greetings, conversations, maintaining friendships, asking for help and directing others. Play improves social skills (Steedly et al 2008).
The researcher thinks that recreational and small games make children feel happy and provide them with joy, psychological security, social security, love, content and stability. Through these games the child acquires knowledge, vocabulary, concepts, experiences and skills to modify his/her behavior. It is necessary for child's physical, mental, social and psychological growth. It helps forming a good citizen who is useful for himself, others and the society.

The researcher thinks that bullying victims need help in improving their social skills to decrease this serious phenomenon. This led the researcher to design a recreational games program to improve social skills for school bullying victims to decrease this phenomenon as, according to the researcher's knowledge, there are no previous Arabic research dealing with this topic.

\section{Aim:}

The current research aims to improve social skills of school bullying victims and decrease the phenomenon of school bullying victims through a recreational games program.

\section{Hypothesis:}

There are statistically significant differences between the pre- and post-measurements of the research group om improving social skills of school bullying victims through a recreational games program in favor of the postmeasurements.

\section{Methods:}

\section{Approach:}

The researcher used the experimental approach (one-group design) with pre- and post-measurements.

\section{Participants:}

Research community ( $\mathrm{n}=230)$ included all students of BILAL IBN RABAH Prep School - Al-Santa Directorate - Gharbia Governorate. Participants $(n=28)$ were purposefully chosen. They were all school bullying victims (12-13 years) with stable middle class families (12.173\% of research community). The researcher assured data normality on all research variables as seen in table (1). 
Table (1)

Descriptive data of participants (Growth Factors - Matson's Evaluation of Social Skills for Youngsters Scale - Bullying Victims Scale) for data normality $(n=28)$

\begin{tabular}{|c|c|c|c|c|c|c|c|}
\hline $\mathrm{S}$ & \multicolumn{2}{|r|}{ Variables } & Measurement & Mean & SD & Kurtosis & Squewness \\
\hline 1 & \multirow{3}{*}{ 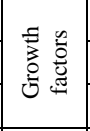 } & Age & Year/month & 12.339 & 0.223 & 1.783 & 1.269 \\
\hline 2 & & Height & $\mathrm{Cm}$ & 146.5 & 1.73 & -0.554 & -0.345 \\
\hline 3 & & Weight & $\mathrm{Kg}$ & 43.692 & 1.875 & -1.028 & -0.047 \\
\hline 4 & \multirow{6}{*}{ 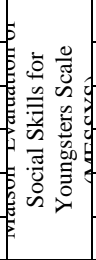 } & Suitable (normal) social skills & Point & 29.785 & 1.397 & 0.903 & -0.816 \\
\hline 5 & & Assertive unsuitable (abnormal) skills & Point & 16.678 & 0.722 & -0.810 & 0.584 \\
\hline 6 & & Disobedience (impulsiveness) & Point & 6.071 & 0.766 & -1.230 & -0.125 \\
\hline 7 & & Over confidence (egotism) & Point & 5.178 & 0.390 & 1.234 & 1.775 \\
\hline \multirow{2}{*}{\begin{tabular}{|l|}
8 \\
9 \\
\end{tabular}} & & Jealousy (withdrawal tendencies) & Point & 4.214 & 0.417 & 0.176 & 1.473 \\
\hline & & Other items & Point & 9.250 & 0.440 & -0.554 & 1.221 \\
\hline 10 & & Sum of social skills Scale & Point & 71.178 & 1.634 & -0.439 & -0.254 \\
\hline 11 & & Bullying victims Scale & Point & 28.107 & 1.474 & -0.509 & 0.101 \\
\hline
\end{tabular}

Table (1) indicated the normality of participants' data as squewness values were between $( \pm 3)$. This means that data was free of radical distributions.

\section{Data collection tools:}

\section{1- Matson's Evaluation of Social Skills for Youngsters Scale (1983) (Arabicized by Abd El-Wahab 2014):}

This is a self-report scale for children with (62) items measuring (6) factors including: Suitable (normal) social skills with (23) items (9-10-12-13-16-20-23-24-28-31-3234-37-40-42-43-44-46-50-52-55-56-59) - Assertive unsuitable (abnormal) skills with (16) items (2-7-11-1417-19-21-22-29-30-39-41-53-60-61-62) - Disobedience (impulsiveness) with (5) items (3-4-5-6-35) - Over confidence (egotism) with (5) items (8-33-36-57-58) Jealousy (withdrawal tendencies) with (4) items (15-3849-54) - Others with (9) items (1-18-25-26-27-45-47-48-
51). Responses are evaluated according three-point-scale (always - sometimes - rarely) with (3-2-1) for acceptable social behaviors and (1-2-3) for non-acceptable social behaviors. Total sum of the scale ranges from 62 to 186 with low scores indicating limitations of social skills and high scores indicating good social skills for interacting with others and the environment in various situations. (Abd El-Wahab 2014: 2-10).

The researcher verified the scale's validity and reliability through a pilot study as he applied the scale to a pilot sample $(n=15)$ from the same research community and outside the main sample from 14-2-2016 to 21-2-2016. Validity was expressed as internal consistency as the researcher calculated correlation coefficients for item and factor, item and sum and factor and sum as seen in tables (2) and (3). Reliability was verified through calculating correlation coefficient between test and retest in addition to Cronbach's Alpha as seen in tables (4) and (5). 
Table (2)

Internal Consistency (Item with factor) of Matson's Evaluation of Social Skills for Youngsters Scale ( $\mathrm{n}=15)$

\begin{tabular}{|c|c|c|c|c|c|c|c|c|c|c|c|c|c|c|c|c|c|}
\hline \multicolumn{3}{|c|}{ First factor } & \multicolumn{3}{|c|}{ Second factor } & \multicolumn{3}{|c|}{ Third factor } & \multicolumn{3}{|c|}{ Fourth factor } & \multicolumn{3}{|c|}{ Fifth factor } & \multicolumn{3}{|c|}{ Sixth factor } \\
\hline $\mathrm{S}$ & $\begin{array}{l}\text { Item } \\
\text { with } \\
\text { factor }\end{array}$ & $\begin{array}{l}\text { Item } \\
\text { with } \\
\text { sum }\end{array}$ & $\mathrm{S}$ & $\begin{array}{l}\text { Item } \\
\text { with } \\
\text { factor }\end{array}$ & $\begin{array}{l}\text { Item } \\
\text { with } \\
\text { sum }\end{array}$ & $S$ & $\begin{array}{l}\text { Item } \\
\text { with } \\
\text { factor }\end{array}$ & $\begin{array}{l}\text { Item } \\
\text { with } \\
\text { sum }\end{array}$ & S & $\begin{array}{l}\text { Item } \\
\text { with } \\
\text { factor }\end{array}$ & $\begin{array}{l}\text { Item } \\
\text { with } \\
\text { sum }\end{array}$ & S & $\begin{array}{l}\text { Item } \\
\text { with } \\
\text { factor }\end{array}$ & $\begin{array}{l}\text { Item } \\
\text { with } \\
\text { sum }\end{array}$ & S & $\begin{array}{l}\text { Item } \\
\text { with } \\
\text { factor }\end{array}$ & $\begin{array}{l}\text { Item } \\
\text { with } \\
\text { sum }\end{array}$ \\
\hline 1 & 0.81 & 0.75 & 1 & 0.78 & 0.83 & 1 & 0.90 & 0.86 & 1 & 0.75 & 0.80 & 1 & 0.82 & 0.87 & 1 & 0.76 & 0.84 \\
\hline 2 & 0.79 & 0.83 & 2 & 0.79 & 0.85 & 2 & 0.87 & 0.82 & 2 & 0.74 & 0.79 & 2 & 0.86 & 0.91 & 2 & 0.80 & 0.76 \\
\hline 3 & 0.70 & 0.76 & 3 & 0.78 & 0.74 & 3 & 0.86 & 0.91 & 3 & 0.83 & 0.90 & 3 & 0.90 & 0.84 & 3 & 0.91 & 0.80 \\
\hline 4 & 0.81 & 0.78 & 4 & 0.73 & 0.80 & 4 & 0.76 & 0.73 & 4 & 0.86 & 0.72 & 4 & 0.79 & 0.74 & 4 & 0.86 & 0.81 \\
\hline 5 & 0.92 & 0.88 & 5 & 0.81 & 0.75 & 5 & 0.87 & 0.92 & 5 & 0.71 & 0.66 & & & & 5 & 0.85 & 0.92 \\
\hline 6 & 0.77 & 0.72 & 6 & 0.71 & 0.77 & & & & & & & & & & 6 & 0.73 & 0.78 \\
\hline 7 & 0.78 & 0.81 & 7 & 0.82 & 0.90 & & & & & & & & & & 7 & 0.88 & 0.90 \\
\hline 8 & 0.86 & 0.90 & 8 & 0.84 & 0.79 & & & & & & & & & & 8 & 0.82 & 0.76 \\
\hline 9 & 0.82 & 0.74 & 9 & 0.92 & 0.88 & & & & & & & & & & 9 & 0.86 & 0.82 \\
\hline 10 & 0.91 & 0.84 & 10 & 0.76 & 0.84 & & & & & & & & & & & & \\
\hline 11 & 0.81 & 0.75 & 11 & 0.83 & 0.88 & & & & & & & & & & & & \\
\hline 12 & 0.80 & 0.87 & 12 & 0.83 & 0.72 & & & & & & & & & & & & \\
\hline 13 & 0.76 & 0.72 & 13 & 0.85 & 0.77 & & & & & & & & & & & & \\
\hline 14 & 0.88 & 0.91 & 14 & 0.74 & 0.83 & & & & & & & & & & & & \\
\hline 15 & 0.91 & 0.88 & 15 & 0.79 & 0.84 & & & & & & & & & & & & \\
\hline 16 & 0.74 & 0.80 & 16 & 0.81 & 0.72 & & & & & & & & & & & & \\
\hline 17 & 0.88 & 0.83 & & & & & & & & & & & & & & & \\
\hline 18 & 0.90 & 0.86 & & & & & & & & & & & & & & & \\
\hline 19 & 0.81 & 0.87 & & & & & & & & & & & & & & & \\
\hline 20 & 0.79 & 0.74 & & & & & & & & & & & & & & & \\
\hline 21 & 0.72 & 0.81 & & & & & & & & & & & & & & & \\
\hline 22 & 0.86 & 0.73 & & & & & & & & & & & & & & & \\
\hline 23 & 0.71 & 0.74 & & & & & & & & & & & & & & & \\
\hline
\end{tabular}

(r) Table value on $\mathrm{P} \leq 0.05=0.497$

Table (2) indicated statistically significant correlations among item and factor and item and sum. This verifies internal consistency of the scale.

Table (3)

Internal Consistency (factor with sum) of Matson's Evaluation of Social Skills for Youngsters Scale ( $\mathrm{n}=15)$

\begin{tabular}{|c|c|c|}
\hline S & Factors & $\mathrm{r}$ \\
\hline 1 & Suitable (normal) social skills & 0.73 \\
\hline 2 & Assertive unsittable (abnormal) skills & 0.81 \\
\hline 3 & Disobedience (impulsiveness) & 0.79 \\
\hline 4 & Over confidence (egotism) & 0.74 \\
\hline 5 & Jealousy (withdrawal tendencies) & 0.77 \\
\hline 6 & Other items & 0.80 \\
\hline
\end{tabular}

(r) Table value on $\mathrm{P} \leq 0.05=0.497$

Table (3) indicated statistically significant correlations between factor and sum. 
Table (4)

test/retest correlations for Matson's Evaluation of Social Skills for Youngsters Scale's reliability ( $\mathrm{n}=15)$

\begin{tabular}{|c|c|c|c|c|c|c|}
\hline \multirow{2}{*}{$\mathrm{S}$} & \multirow{2}{*}{ Factors } & \multicolumn{2}{|c|}{ Test } & \multicolumn{2}{|c|}{ Retest } & \multirow{2}{*}{$\mathrm{r}$} \\
\hline & & Mean & $\mathrm{SD} \pm$ & Mean & $\mathrm{SD} \pm$ & \\
\hline 1 & Suitable (normal) social skills & 29.800 & 1.740 & 29.866 & 1.684 & 0.892 \\
\hline 3 & Disobedience (impulsiveness) & 6.200 & 0.861 & 6.266 & 0.798 & 0.851 \\
\hline 4 & Over confidence (egotism) & 5.200 & 0.414 & 5.200 & 0.676 & 0.868 \\
\hline 5 & Jealousy (withdrawal tendencies) & 4.266 & 0.457 & 4.333 & 0.487 & 0.853 \\
\hline 6 & Other items & 9.266 & 0.457 & 9.400 & 0.632 & 0.839 \\
\hline 7 & Sum of the scale & 71.400 & 1.843 & 71.933 & 2.218 & 0.827 \\
\hline
\end{tabular}

(r) Table value on $\mathrm{P} \leq 0.05=0.497$

Table (4) indicated statistically significant correlations between test and retest and this indicates scale reliability.

Table (5)

Cronbach's Alpha for Matson's Evaluation of Social Skills for Youngsters Scale's reliability (n=15)

\begin{tabular}{|c|c|c|}
\hline $\mathrm{S}$ & Scale & Alpha \\
\hline 1 & Matson's Evaluation of Social Skills for Youngsters & 0.855 \\
\hline
\end{tabular}

Table (5) indicated that Cronbach's Alpha for the scale $=$ three-point scale (never - once - more than once) with $(0$ 0.855 which is a high value indicating the scale's 1-2) points respectively. Sum of the scale ranges from 0 to reliability. 34 (Al-Bahas 2012).

\section{2- Bullying Victim Scale (Frienden et al 2010)} (Arabicized by Al-Bahas 2012):

This scale includes (17) items measuring the degree of harm over students due to being victims for bullying (physical - verbal - psychological - electronic) during the academic year. Responses are evaluated according to a
The researcher verified the scale's validity and reliability through the pilot study. Validity was expressed as internal consistency as the researcher calculated correlation coefficients for item and sum as seen in table (6). Reliability was verified through calculating correlation coefficient between test and retest in addition to Cronbach's Alpha as seen in tables (7) and (8).

Table (6)

Internal Consistency (Item with sum) of Bullying Victim Scale $(\mathrm{n}=15)$

\begin{tabular}{|l|l|l|}
\hline \multirow{2}{*}{$\mathrm{S}$} & Items & $\mathrm{r}$ \\
\cline { 3 - 3 } & & Item with sum \\
\hline 1 & 2 & 0.92 \\
\hline 2 & 3 & 0.87 \\
\hline 3 & 4 & 0.88 \\
\hline 4 & 5 & 0.91 \\
\hline 5 & 6 & 0.89 \\
\hline 6 & 7 & 0.88 \\
\hline 7 & 8 & 0.87 \\
\hline 8 & 9 & 0.90 \\
\hline 9 & 10 & 0.84 \\
\hline 10 & 11 & 0.89 \\
\hline 11 & 12 & 0.85 \\
\hline 12 & 13 & 0.90 \\
\hline 13 & 14 & 0.86 \\
\hline 14 & 15 & 0.92 \\
\hline 15 & 16 & 0.87 \\
\hline 16 & 17 & 0.91 \\
\hline 17 & & 0.89 \\
\hline
\end{tabular}

(r) Table value on $\mathrm{P} \leq 0.05=0.497$ 
Table (6) indicated statistically significant correlations among item and factor and item and sum. This verifies internal consistency of the scale.

Table (7)

test/retest correlations for Bullying Victim Scale's reliability $(n=15)$

\begin{tabular}{|c|c|c|c|c|c|c|}
\hline \multirow{2}{*}{$S$} & \multirow{2}{*}{ Scale } & \multicolumn{2}{|c|}{ Test } & \multicolumn{2}{|c|}{ Retest } & \multirow{2}{*}{$\mathrm{r}$} \\
\cline { 2 - 6 } & & Mean & SD \pm & Mean & SD \pm & \\
\hline 1 & Bullying Victim Scale & 27.466 & 0.516 & 27.600 & 0.632 & 0.831 \\
\hline
\end{tabular}

(r) Table value on $\mathrm{P} \leq 0.05=0.497$

Table (7) indicated statistically significant correlations between test and retest and this indicates scale reliability.

Table (8)

Cronbach's Alpha for Bullying Victim Scale's reliability $(\mathrm{n}=15)$

\begin{tabular}{|c|c|c|}
\hline $\mathrm{s}$ & Scale & Alpha \\
\hline 1 & Bullying Victim Scale & 0.835 \\
\hline
\end{tabular}

Table (8) indicated that Cronbach's Alpha for the scale $=\bullet$ Main part: this part includes (40) minutes of recreational 0.835 which is a high value indicating the scale's reliability.

3- The Recreational Games Program (by the researcher):

The researcher chose a group of recreational games and activities that promote happiness, joy, content, comfort, security, self-confidence and independence to improve social skills of bullying victims. Experts $(n=9)$ agreed on the importance of the recommended games with agreement percentage ranging from $88.89 \%$ to $100 \%$.

\section{Aim:}

The program aims to improve social skills of bullying victims and achieve personal happiness for them to decrease the phenomenon of school bullying victims.

\section{Program principles:}

- Considering psychological, social, mental and physical characteristics of bullying victim students

- Considering progression, variance and individual differences

- Considering rest intervals

- Considering safety precautions during performance

- Using colorful tools and equipment to make games more fun

- Providing encouragement and praise for children

- Applying games with songs and music

\section{Program contents:}

- Preliminary part: It aims to prepare students physically and psychologically and make them feel happy and encouraged for positive involvement. This part includes (10) minutes of recreational games and activities. games and activities that are suitable for the unit's objective (improvement of social skills for bullying victims and decreasing bullying victims' phenomenon).

- Conclusion: This part aims to restore normal condition of the body through cool down. It includes (10) minutes of recreational games and activities.

- The researcher presented the preliminary draft of the program to (9) experts specialized in sports recreation, sociology, psychology and mental health. Experts eliminated a few games and modified some of them.

\section{Recreational games:}

- Games are played among pupils in the form of relay and the winner team is the team that finishes the game first.

- All activities and games are introduced in accompaniment with music and songs

- All activities and games have objectives and slogans hidden in them. Pupils should find them during the game, keep them and then say them at the end. This includes: I keep my promises - I don't get angry easily I love myself - I depend on myself - I always want to be first - I help my friends - I make my friends happy - I feel happy when I do something good - I like my abilities - I like cooperation - I don't make sounds that annoy others - I preserve others' properties just like mine - I don't make fun of others - I keep others' secrets - I don't feel afraid of talking to others - I don't like making others annoyed - I don't lie - I'm honest I'm brave - I'm tough - I thank who helps me - I become happy when someone does nice things to me - I don't hurt others' feelings - I like sharing activities with others - I do nice things to others - I like leadership - I don't make anyone upset - I like mixing with others I'm satisfied with my appearance and glad with it - I can express myself effectively and clearly - I'm handsome - 
I feel happy when I'm with the group - I can cope with difficulties - I can challenge and face challenges - my abilities are not less than anyone else - I'm positive and pessimistic - I challenge myself - I feel content and secure - I cope with my problems - I like hope and pessimism - I trust my abilities - I express my opinions - I confirm myself and I'll be what I want to be - I can make decisions - I can defend myself and avoid harm ... etc.

- All pupils were provided with encouragement and complements in addition to giving them gifts and rewards.

- The program includes (32) units applied along (2) months (4 units per week for 8 weeks). The researcher applied the program directly with instructions for students to be self-dependent while facing challenges according to their abilities.
The researcher performed the second pilot study from 232-2016 to 25-2-2016 through applying some units to the pilot sample to verify its suitability.

\section{Measurements:}

Pre-measurements for the two scales were taken from 282-2016 to 29-2-2016. The recommended recreational games program was applied for (8) weeks from 6-3-2016 to 1-5-2016. Post-measurements were taken from 3-52016 to $4-5-2016$.

\section{Statistical treatments:}

The researcher used SPSS software to calculate the following: mean - median - SD - Kurtosis - squewness correlation coefficient (r) - Cronbach's Alpha - (t) test Improvement percentage.

\section{Results:}

Table (9)

Difference significance between the means of pre- and post-measurements of Matson's Evaluation of Social Skills for Youngsters Scale and Bullying Victim Scale $(\mathrm{n}=28)$

\begin{tabular}{|c|c|c|c|c|c|c|c|c|c|c|}
\hline \multirow{2}{*}{ S } & \multirow{2}{*}{\multicolumn{2}{|c|}{ Scale }} & \multicolumn{2}{|c|}{ Pre- } & \multicolumn{2}{|c|}{ Post- } & \multirow{2}{*}{$\begin{array}{c}\text { Means } \\
\text { difference }\end{array}$} & \multirow{2}{*}{$\begin{array}{l}\text { Standard } \\
\text { Error }\end{array}$} & \multirow{2}{*}{$\mathrm{T}$} & \multirow{2}{*}{$\begin{array}{c}\text { Improvement } \\
\text { percentage (\%) }\end{array}$} \\
\hline & & & Mean & $\mathrm{SD}+$ & Mean & $\mathrm{SD} \pm$ & & & & \\
\hline 1 & \multirow{6}{*}{ 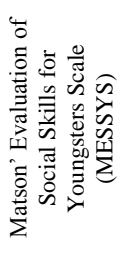 } & Suitable (normal) social skills & 29.785 & 1.397 & 65.071 & 0.875 & 35.285 & 0.223 & 157.982 & 118.46 \\
\hline 2 & & Assertive unsittable (abnormal) skills & 16.678 & 0.722 & 41.928 & 1.274 & 25.250 & 0.255 & 98.928 & 151.39 \\
\hline 3 & & Disobedience (impulsiveness) & 6.071 & 0.766 & 13.750 & 0.585 & 7.678 & 0.136 & 56.211 & 126.47 \\
\hline 4 & & Over confidence (egotism) & 5.178 & 0.390 & 13.928 & 0.262 & 8.750 & 0.097 & 89.351 & 168.98 \\
\hline 5 & & Jealousy (withdrawal tendencies) & 4.214 & 0.417 & 11.142 & 0.448 & 6.928 & 0.114 & 60.678 & 164.40 \\
\hline 6 & & Other items & 9.250 & 0.440 & 23.178 & 0.772 & 13.928 & 0.170 & 81.916 & 150.57 \\
\hline- & \multicolumn{2}{|r|}{ Sum of social skills Scale } & 71.178 & 1.634 & 169.00 & 2.403 & 97.821 & 0.522 & 187.348 & 137.43 \\
\hline 1 & \multicolumn{2}{|r|}{ Bullying victims Scale } & 28.107 & 1.474 & 8.035 & 1.400 & 20.071 & 0.290 & 69.061 & 71.41 \\
\hline
\end{tabular}

(T) Table value on $\mathrm{P} \leq 0.05=2.052$

Table (9) indicated statistically differences between the means of pre- and post-measurements on the social skills scale as ( $\mathrm{t}$ ) calculated values were higher than its table value with (187.348) as the highest value. The mean value for the pre-measurement was (71.178) while the mean value for the post-measurement was (169.00). in addition, table (9) indicated statistically differences between the means of pre- and post-measurements on the bullying victims' scale with $(\mathrm{T})$ calculated value (69.061) higher than its table vale. The mean value for the premeasurement was (28.107) while the mean value for the post-measurement was (8.035).

\section{Discussion:}

Table (9) indicated that improvement percentage for Matson's Evaluation of Social Skills for Youngsters Scale was $(137.43 \%)$ and $(71.41 \%)$ for Bullying Victim Scale. This indicates the positive effects of the recommended recreational games program om improving social skills of bullying victim children and decreasing the bullying victims' phenomenon. This is because the program includes games and activities that work on improving social skills, interaction with others, friendship formation, cooperation, self-confidence, independence, responsibility, problem solving, courage, social participation and decreased fears. This meets the needs, interests and desires of bully victim children and makes them feel safe, loved, comforted, independent, stable, responsible and dangerfree.

Bully victims feel lonely, stressed and depressed. They are more anxious, more vulnerable to fear and less strong compared to their normal peers. Therefore, they need 
assertiveness and improved social skills and behaviors in addition to preventive programs that help them avoid depression (Macklem 2004). They suffer from fear. Weakness, sadness and weak social skills. These programs help them increase self-confidence and prevent danger of being bullied in addition to improving social skills (Claire et al 2005).

Bully victims have problems in social behaviors, depression and anxiety (Cheng et al 2011). They suffer from mal-social adaptation, depression and anxiety (Caroline et al 2014). School bullying has harmful effects over victims and affects their social, mental, psychological and physical aspects (Sandra et al 2015).

Training programs for social skills work on decreasing problems faced by bully victims. These preventive interventions improve social skills and restore positive life without fear for bully victims in addition to decreasing the rates of bullying at schools (Koiv 2012).

Recreational activities help children form new relations and friendships in addition to supporting social interaction and acquisition of social skills and behaviors (Dorak et al 2012). It improves quality of life and decreases stress (Kuo 2013). Recreational activities allow individuals to meet new friends, make new relations, relieve stress, improve health and fitness and feel happy and joyful (Forrester 2014). It decreases psychological pain and provides psychological supports in addition to improving quality of life, social relations and social interaction. It has various health, physical, mental, social and psychological benefits (Sruebinger 2015).

Recreational activities programs improve cardiopulmonary capacity, physical fitness and health (Qana 2016). It improves physical, mental, social and psychological health in addition to supporting social and intellectual development and social integration and interaction. This creates strong societies.

The researcher indicates that the recommended recreational games program with all its components works on improving problem solving, coping, independence, self-confidence, good relations, cooperation, social interaction and social skills. It also decreases stress, anxiety and fear. Therefore, it decreases the rate of bullying victims' phenomenon. Such programs aim to bring up great joy. It is very useful in helping bully victims to grow in a balanced manner. It is a daily necessity due to its social and psychological benefits. This proves the research hypothesis.

\section{Conclusions:}

1- The recommended recreational games program had positive effects on improving social skills of school bullying victims, with Improvement percentage $137.43 \%$.

2- The recommended recreational games program had positive effects on decreasing the school bullying victims' phenomenon, with Improvement percentage $71.41 \%$.

\section{Recommendations:}

1- Initiating the recommended recreational games program for school bullying victims

2- Designing more recreational and small games programs specialized in physical, mental, social, psychological and ethical aspects for both bully and bully victim students in other age groups to decrease this serious phenomenon among school students

3- Paying more care for students in general through using recreational games for educating and nurturing them

\section{References:}

1- Abd El-Wahab, Amany Abd El-Maksoud (2014): Evaluation of Social Skills Inventory (ESSI). The AngloEgyptian Library, Cairo - Egypt (in Arabic)

2- Agnes Ebi Maliki , C.G.Asagwara \& Julie E. Ibu (2009) : Bullying Problems among School Children, J Hum Ecol, 25(3), $209-213$.

3- Al-Bahas, Sayed Ahmed (2012): Psychological security for bully and bully victim students: a psychometric clinical study. Journal of Faculty of Education - Banha University, Vol.23, no.92, PP: 349-395 (in Arabic)

4- Alikasifoglu M, Erginoz E, Ercan O, Uysal O, Albayrak-Kaymak D (2007) : Bullying behaviours and psychosocial health: results froma cross-sectional survey among high school students in Istanbul, Turkey, European Journal of Pediatrics, 166 (12), 1253 - 1260 .

5- Allen, K (2010) : A Bullying Intervention System: Reducing Risk and Creating Support for Aggressive Students, Presenting School Failure, Journal of Social Psychology, vol 54 (3), 199 - 209.

6- Archer, Ireland, J\& Power, C (2007) : Differences between bullies and victims, and men and women, on aggression - related variables among prisoners, British Journal of Social Psychology, vol 46, 299 - 322 .

7- Caroline B.R. Evans, MarkW. Fraser, Katie L. Cotter (2014) : The effectiveness of school-based bullying 
prevention programs : A systematic review, Aggression and Violent Behavior, vol 19, 532-544 .

8- Chih-Yao Lo, Hsin-I Chang, Yu-Teng Chang (2009) : Research on Recreational Sports Instruction Using an Expert System, Springer-Verlag Berlin Heidelberg, 250 262 .

9- Chin-Tsai Kuo (2013) : The effect of recreational sport involvement on Work stress and quality of life in central Taiwan, Social Behavior and Personality, vol 41 (10), 1705-1716.

10- Claire L. Fox, Michael J. Boulton (2005) : The social skills problems of victims of bullying : Self, peer and teacher perceptions, British Journal of Educational Psychology, 75, 313-328.

11- Danny Wayne Pettry (2006) : Building Social Skills through Activities, Certified Therapeutic Recreation Specialist, United States of America .

12- Debra J. Pepler, Wendy M. Craig, Jennifer A. Connolly, Amy Yuile, Loren McMaster \& Depeng Jiang (2006) : A Developmental Perspective on Bullying, Aggressive Behavior, vol 32, 376 - 384 .

13- Fox. C., Boulton. M.J (2005) : The social skills problems of victims of bullying: Self, peer and teacher perceptions, British Journal of Educational Psychology, $75,313-328$

14- Gayle L. Macklem (2004) : Bullying and Teasing Social Power in Children's Groups, Library of Congress Cataloging-in-Publication Data .

15- Georg Stuebinger (2015) : Sports and Exercise Training as Therapy in Cancer, Springer, Library of Congress Control, Graz, Austria, 2015.

16- Hopkins, L; Taylor, L. M; Bowen, E \& Wood, C (2013): A qualitative study investigating adolescents understanding of aggression, bullying and violence, Children and Youth Services Review, vol 35 (4), 685 693

17- Kathlyn M. Steedly , Amanda Schwartz , Michael Levin, M.A. \& Stephen D. Luke (2008) : Social Skills and Academic Achievement, National Dissemination Center for Children with Disabilities, Evidence for Education, vol 3 (2).

18- Kristi Kõiv (2012) : Social skills training as a mean of improving intervention for bullies and victims, Procedia Social and behavioral sciences, vol 45, $239-246$.
19- Lawrence E. Shapiro (2004) : 101 Ways to teach children social skills, A ready-to-use, Reproducible Activity Book, The Bureau for At-Risk Youth, The Guidance Group, United States of America .

20- Oana Maria Ganciu (2016) : Recreational sports - a form of health education, Bulletin of the Transilvania University of Braşov, vol 9 no (58), 31 - 34 .

21- R.Ferudun Dorak, Lale Yildiz, Civan Sortullu (2012) : The effects of eight weeks of sports activities on selfsufficiency, social skills and some physical fitness parameters in children 9-10 years of age, Procedia - Social and Behavioral Sciences, vol 47, 1286 - 1291 .

22- Richard Kraus (2015) : Recreation and leisure in modern society, 10th Edition, Jones and Bartlett Publishers, Canada.

23- Sandra K. M. Tsang, Eadaoin K. Hui (2015) : Preventing and Combating School Bullying: A Conceptual Review, Springer Science, Business Media Singapore, 47 -58 .

24- Schwartz, D., Farver, J.M., Chang, L., \& Lee-Shin, Y (2002) : Victimization in South Korean children's peer groups, Journal of Abnormal Child Psychology, 30, 113125 .

25- Scott A. Forrester (2014) : The Benefits of Campus Recreation, NIRSA Headquarters, Corvallis, Oregon .

26- Sylvia Titze, Dafna Merom, Chris Rissel, Adrian Bauman (2014) : Epidemiology of cycling for exercise, recreation or sport in Australia and its contribution to health-enhancing physical activity, Journal of Science and Medicine in Sport, vol 17, 485-490.

27- Taha, Taha Ibrahim (2006): Introduction to Recreation. Dar Al-Wafaa Press - Alexandria - Egypt (in Arabic)

28- Tolba, Mahmoud Isamail (2010): Psychology of recreation and leisure time. Islamic Graphic - Cairo Egypt (in Arabic)

29- Walters, J: Recognizing Bullying as Aggression (2009) : A Guide for School Counselors, Ph.D. , The Graduate School, University of Wisconsin Stout .

30- Ying-Yao Cheng, Li-Ming Chen, Kun-Shia Liu\& YiLing Chen (2011): Development and Psychometric Evaluation of the School Bullying Scales: A Rasch Measurement Approach, Educational and Psychological Measurement, 71 (1), $200-216$. 